\title{
Technology readiness levels for advanced nuclear fuels and materials development
}

\author{
Authors: W. J. Carmack ${ }^{\mathrm{a}}$, L. A. Braase ${ }^{\mathrm{a}}$, R. A. Wigeland ${ }^{\mathrm{a}}$, and M. Todosow ${ }^{\mathrm{b}}$ \\ ${ }^{a}$ Idaho National Laboratory, Idaho Falls, Idaho \\ ${ }^{b}$ Brookhaven National Laboratory, Upton, New York \\ Corresponding author: Jon Carmack \\ 2525 Fremont Ave \\ P.O. Box 1625 \\ Idaho Falls, ID 83415-3840 \\ jon.carmack@inl.gov \\ 208-526-5424
}

\begin{abstract}
The Technology Readiness process quantitatively assesses the maturity of a given technology. The National Aeronautics and Space Administration (NASA) pioneered the process in the 1980s to inform the development and deployment of new systems for space applications. The process was subsequently adopted by the Department of Defense (DoD) to develop and deploy new technology and systems for defense applications. It was also adopted by the Department of Energy (DOE) to evaluate the maturity of new technologies in major construction projects.

Advanced nuclear fuels and materials development is needed to improve the performance and safety of current and advanced reactors, and ultimately close the nuclear fuel cycle. Because deployment of new nuclear fuel forms requires a lengthy and expensive research, development, and demonstration program, applying the assessment process to advanced fuel development is useful as a management, communication, and tracking tool. This article provides definition of technology readiness levels (TRLs) for nuclear fuel technology as well as selected examples regarding the methods by which TRLs are currently used to assess the maturity of nuclear fuels and materials under development in the DOE Fuel Cycle Research and Development (FCRD) Program within the Advanced Fuels Campaign (AFC).
\end{abstract}

Keywords: Advanced Nuclear Fuel Technology Readiness Level 


\section{Technology readiness levels for advanced nuclear fuels and materials development}

\section{Introduction}

A Technology Readiness Assessment (TRA) evaluates technology maturity using the TRL scale and was pioneered by NASA in the 1980s [1], [2] for space technology. The TRL scale ranges from 1 (basic principles observed) through 9 (total system used successfully in project operations). In 1999 the DoD adopted NASA's TRLs to assess technology maturity in the development process [3] of defense-related technologies and in 2007, the DOE's Office of Environmental Management (EM) conducted several pilot TRAs using tailored TRL definitions. The reported benefits of this activity: providing a structured, criteria-based, and clearly documented assessment; identifying specific actions to reduce risk; assisting in comparing candidate technologies, promoting decision-making discipline; and improving technical communication ultimately resulted in the generation of the DOE TRA Guide, DOE G 413.3A [4]. The TRA approach and the guide have been used by DOE in assessment of capital projects. The effort described in this paper follows the DOE TRA Guide and applies the methodology to nuclear fuels and material systems.

Advanced nuclear fuels research is a critical part of the DOE's FCRD program aimed at developing advanced technologies for the nuclear fuel cycle. TRLs provide a framework for identifying and prioritizing needed activities associated with nuclear fuels and materials research and development. This paper discusses the approach employed by the AFC in the DOE FCRD Program for identifying TRLs for advanced nuclear fuels and materials. The approach includes two elements: 1) descriptive material and "definitions" for TRLs developed by the AFC and described in [5], and 2) questions for each TRL based on the information in [4] and the example questionnaire developed by the Air Force Research Laboratory (AFRL), modified for application to advanced nuclear fuels and materials.

\section{The Technology Readiness Assessment Process}

TRLs are measures used to evaluate the technical maturity of evolving technologies during development. The definition and assessment of TRLs are part of an overall process for performing a TRA. The process provides information regarding the state of technology development as well as the required research and development to bring a technology to a desired level of maturity.

There are three essential steps to the TRA process described in the TRA Guide. All steps must be completed to inform a decision-making process.

1. Identify the Critical Technology Elements (CTE): It is important to identify the CTEs of a system to insure all technologies required for development of the system (such as a replacement fuel assembly or reprocessing technology) are included in the technology development plan. Complete identification and documentation supporting a sufficient state of maturation is critical for the supporting technologies. Further, documentation is essential for those supporting technologies requiring research and development $(\mathrm{R} \& \mathrm{D})$ to prove they have been accurately characterized. 
2. Assess the TRL for each CTE: The TRL for each technology requiring R\&D (the CTEs) provides an assessment of the current status of technology maturity and includes specific requirements for each technology that must be met at each TRL. This provides the background required for completion of successful system development plans.

3. Develop a Technology Maturation Plan (TMP) for each CTE based on the TRL: The TMP specifies the R\&D and industrialization activities that must occur to complete development of the system. This includes testing requirements, facility needs, and estimates of the time and cost to complete development. The scope of the TMP may depend on the current TRL for each CTE, as well as the ability to predict the effort required to successfully progress a technology from one TRL to the next; this may become more difficult if the CTE is at a low TRL. However, the TMP should be able to provide a credible estimate of the overall effort required for technology development. This estimate facilitates assessment of the overall risk associated with system development as well as support for any selections or prioritizations that may need to occur between competing technologies.

Although the overall TRA approach and the use of CTEs, TRLs, and TMPs is specific to [4] and may not reflect the use of the TRL in all contexts/situations, all three parts of the TRA approach described above are appropriate and necessary to ensure the successful development of fuel cycle systems, whether an advanced fuel, a separations technology, or any other part of the nuclear fuel cycle.

The application/utilization of the TRA process described above to the development of advance nuclear fuels and materials recognizes that the ultimate objective is to implement them in a reactor. Several elements need to be available in order to accomplish this, e.g. fuel in appropriate form/cladding/rods/assemblies/. In principle, each of these can consist of sub-elements. For example, each could be a CTE. The TRL assessment approach is carried out in two parts by use of questionnaires. The first part focuses on each CTE at the component level (e.g., nuclear fuel) for each TRL, and the second, an assessment of the status of technology integration (e.g. at subcomponents such as the fuel rod and assembly component level) for each TRL reflecting the level of integration between all of the technology elements, including CTEs. (Note that the DOE Guide assesses both the CTE TRL and the system TRL in the context of the same questionnaire.) Performing the assessment in two steps affords a clearer identification of the stage of development for each CTE, integration of the technologies, and source of development needs.

Using TRLs helps technology development decision makers prioritize activities concerning the development and progression of technology. They are one of many tools used to assess and manage the progress of research and development activity within an organization and the TRLs provide a common understanding of a technology's status. TRLs can provide input to risk management decisions, funding allocation, and transfer of technology from initial conceptualization through eventual deployment.

\section{Technology readiness levels}

Technologies are subjected to experimentation, refinement, and increasingly realistic testing, evaluation, and eventual qualification for use in licensed commercial facilities and systems. Nuclear reactor fuels and materials are developed through a sequence of activities, often iteratively. To measure and indicate technical progress with a fuel concept or design, a TRL scale can be applied [6]. A TRL number is obtained once the full description of that level has been achieved. For example completing the elements of TRL 4 does not make a technology TRL 5. The TRL 5 designation is given once all elements of TRL 5 have been completed. 


\subsection{TRL definitions}

Full maturity of a nuclear fuel system requires long-term routine operations of commercial fabrication plant(s) supplying fuels to operating reactors. At full maturity adequate statistical data are available for fuel fabrication and performance, and the system is optimized within the constraints of the performance envelope. This level of maturity is assigned a numerical score of 9 for the corresponding TRL. At the other end of the spectrum, when a new concept is proposed and it is shown that the concept is viable based on first principles assessment, a numerical score of 1 is assigned for the corresponding TRL. The intermediate TRL levels are defined, for application to nuclear fuel and materials technology, in a manner analogous with the general TRL definitions of reference 8. The definition of the TRL levels is based on a logical progression of the work, while considering fabrication and performance testing activities in tandem. Satisfaction of the criteria in Figure 1 determines the achievement of the corresponding TRL level.

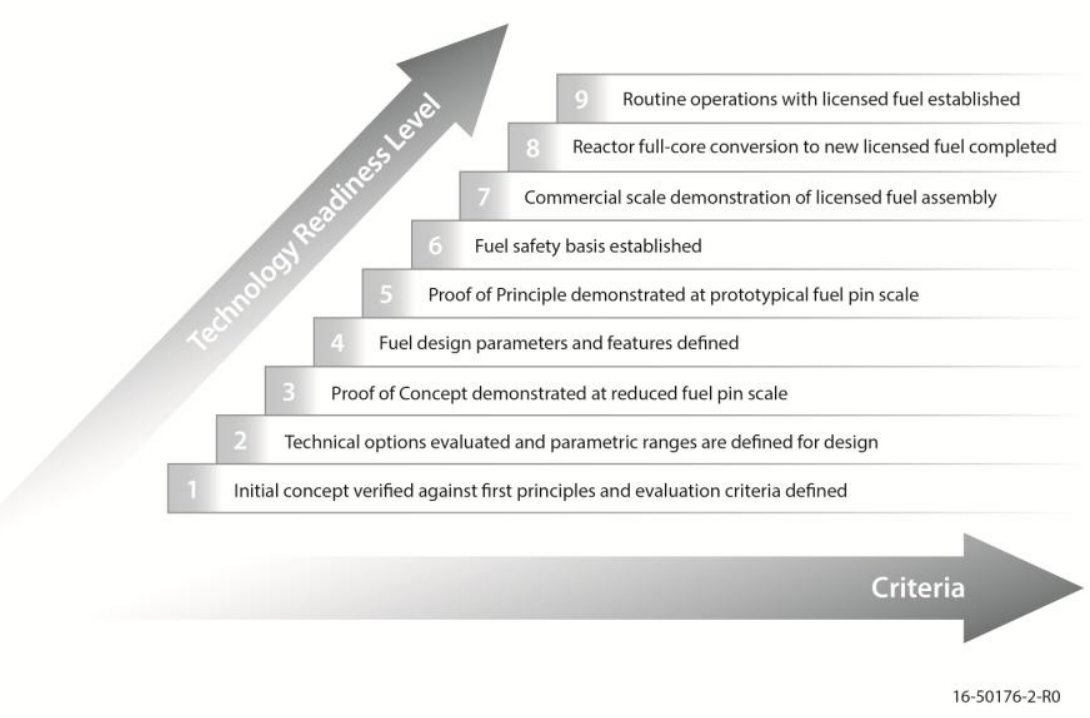

Figure 1. High Level TRL Completion Criteria for Nuclear Fuels and Materials

The TRLs are divided into three major functional categories or phases; TRL 1-3: Proof-of-Concept, TRL 4-6: Proof-of-Principle, and TRL 7-9: Proof-of-Performance. All the criteria in a given level must be completed before the CTE is considered achieving that level designation.

\subsubsection{Proof-of-Concept: TRLs 1 through 3}

The Proof-of-Concept phase of development for new nuclear fuels is initiated with design of a reactor system and identification of the technical and functional requirements for a base fuel system. The first three phases for new nuclear fuel system development are illustrative of an early research and development program. The initial concepts are identified and the key attributes for performance evaluated. Moving from this phase of R\&D to the Proof-of-Concept phase requires that initial bench scale fabrication capabilities have been established and utilized to primarily performing initial laboratory 
experiments to measure key material properties of the fuel system. Initial separate effects irradiation experiments may be performed to test key properties of the material system.

TRL 1: A new fuel concept is proposed. Typically reactor design drives the need to identify candidate fuel systems based on technical and functional requirements for the reactor system. At TRL 1, the technical fuel system options are identified, relevant literature data surveyed, and the performance criteria identified for a candidate system.

TRL 2: The technical options have been identified and preliminary evaluation is underway. Performance range and fabrication process parametric ranges have been identified based on analysis using available data. Key properties determining performance are identified and detailed evaluation including experimental measurements is underway, possibly including separate effects measurements at the bench scale.

TRL 3: Concepts are verified through laboratory scale experiments and characterization. Fabrication of candidate samples is accomplished using surrogates and laboratory scale processes. Base material properties measurements and characterization are performed. Some preliminary irradiation evaluation on bench scale fabrication materials may be underway using test reactors in relevant irradiation conditions, but maybe not fully prototypic irradiation conditions.

\subsubsection{Proof-of-Principle: TRLs 4 through 6}

Progressing from Proof-of-Concept to Proof-of-Principle requires establishing fabrication capability for representative material at least at the laboratory scale (1-10 kg quantities) and progressing to in-pile irradiation testing. A number of research and development activities are conducted during the proof-ofprinciple phase. Fabrication processes established at bench-scale are scaled to the laboratory scale (1$10 \mathrm{~kg}$ quantities) and possibly evaluated for scalability to commercial scale. These larger scale capabilities are utilized to fabricate fuel to be tested and evaluated in relevant and prototypic environments. Transient testing is initiated and progressing beyond the Proof-of-Principle phase requires transient performance evaluation with prototypic fuel irradiated to representative burnup(s).

TRL 4: Technologies at this level of maturity are distinguished by research and development activities conducted at bench scale fabrication and relevant condition irradiation and environmental condition testing. At TRL 4 fabrication of samples using stockpile materials at bench-scale yielding small fuel elements, rodlets, and small scale pin configurations. Irradiation testing of these small samples (rodlets and small pins) is conducted in relevant environments but possibly not fully prototypic of a mature reactor system. Typically irradiation testing is conducted in a test reactor system having the design parameters and features established representative of the desired reactor system. Data generation should be focused on compiling the basic performance property data needed to understand the fuel system performance and behavior in a representative reactor system.

TRL 5: TRL 5 is an advancement over TRL 4 with an increase to the fabrication of full scale fuel elements using laboratory scale fabrication capabilities with subsequent pin-scale irradiation testing conducted in relevant prototypic steady-state irradiation environments. Feedstock materials used in fabrication and irradiation testing are representative of prototypic conditions but may not be from a source expected during proof-of-principle operation. Limited transient testing and possibly lead test rod (LTR) testing could be conducted at the TRL 5 level but the LTR testing would require compatibility with the test reactor assembly level design. The primary performance parameters will have been established with representative compositions under normal operating conditions and the fuel behavior models will have been developed for use in fuel performance code(s). 
TRL 6: Technologies at TRL 6 are at an intermediate step between the Proof-of-Principle and the Proofof-Performance phases. A key attribute of nuclear fuel systems at TRL 6 is that there are activities conducted leading to an understanding of the fuel system performance and behavior in off-normal or transient conditions. This level of understanding is necessary to achieve advancement past TRL 6 where regular assembly level testing and operation is conducted. At TRL 6 fabrication of engineering-scale test pins using prototypic feedstock materials and fabrication processes is conducted. Fuel pin irradiation testing and performance verification is conducted in prototypic irradiation environments. A predictive fuel performance code is available with the capability for assembly level performance analysis and has been qualified with the data generated from the prototypic experimental data. The safety basis for Lead Test Assembly (LTA) testing and operation will be established.

\subsubsection{Proof-of-Performance: TRL 7 through 9}

The Proof-of Performance phase of nuclear fuel system technology is clearly distinguished from the proof-of-principle phase by increasing the scale of fabrication to engineering and commercial scales. The fuel system technology is utilized at commercial scale moving from irradiation of increasing numbers of assemblies "through lead test assemblies" to full core and multiple reactor systems as a robust industrial and commercial basis.

TRL 7: TRL 7 represents the established capability to fabricate test assemblies using prototypic feedstock materials at engineering-scale and using prototypic fabrication processes. It also includes the ability to irradiate at the assembly level in prototypic irradiation environments generating the data needed to validate a predictive fuel performance modeling and simulation code capable of assembly level analyses. The safety basis is established for full core operations in order to move beyond TRL 7 .

TRL 8: TRL 8 designates that a few core loads of fuel have been fabricated and full core operation of a prototype reactor with such fuel has been accomplished.

TRL 9: TRL 9 designates that the fuel technology is routinely conducted at commercial-scale and normal operations are underway. There may be multiple reactors operating with licensed fuel technology available from a commercial vendor.

\subsubsection{Determining technology readiness levels}

Three efforts have been identified world-wide providing a proposed definition of criteria for nuclear fuels and materials [7], [8], [9]. These efforts and criteria have been considered in the definition of criteria in this paper. The determination of TRLs is a structured process. As discussed above, once the CTEs have been identified, responses to a series of questions specific to a given stage of technology maturity are used to determine the appropriate TRL. The TRL is defined when all the questions appropriate to that TRL level receive a positive "YES" response and appropriate justification is provided. Questionnaires have been developed for use by the AFC as described above. Examples of the questionnaires for TRL1, TRL6, and TRL9 are shown in the Appendix and demonstrate the progression of the evolution of a given technology from conception (TRL1), to the completion of the R\&D phase (TRL6), until full-scale commercial implementation (TR9). Note that the questionnaires were intended to be somewhat generic/ technology neutral, although they recognize some of the specific needs of the AFC. However, there is a need to define terms such as "relevant or prototypic environment" and "bench scale or engineering scale" to clarify what is meant or intended when the questionnaires are used in the context of advanced nuclear fuels and materials.

Therefore, as a complement to the questionnaires for determining the appropriate TRL for advance nuclear fuel and materials there are two elements used to evaluate the maturity of a new fuel type in terms of readiness for deployment: 
A. Fabrication Process Maturity, which measures how well the fabrication process is understood and validated.

B. Fuel Performance Maturity, which measures how well the in-pile performance of the fuel is understood and validated.

A TRL definition that provides a balance between these two elements is essential. Testing a very mature fabrication process at very large scales for fuels with large uncertainties in its performance would not be effective. On the other hand, collecting performance data through large-scale testing without a mature definition of the fabrication process is equally unbalanced. As shown in Figure 2, there are two attributes identified for each element to assess TRL levels for nuclear fuel systems. For each attribute, there are distinct bins against which the state-of-knowledge can be compared. The TRL Evaluation Criteria are discussed in detail in the following subsection.

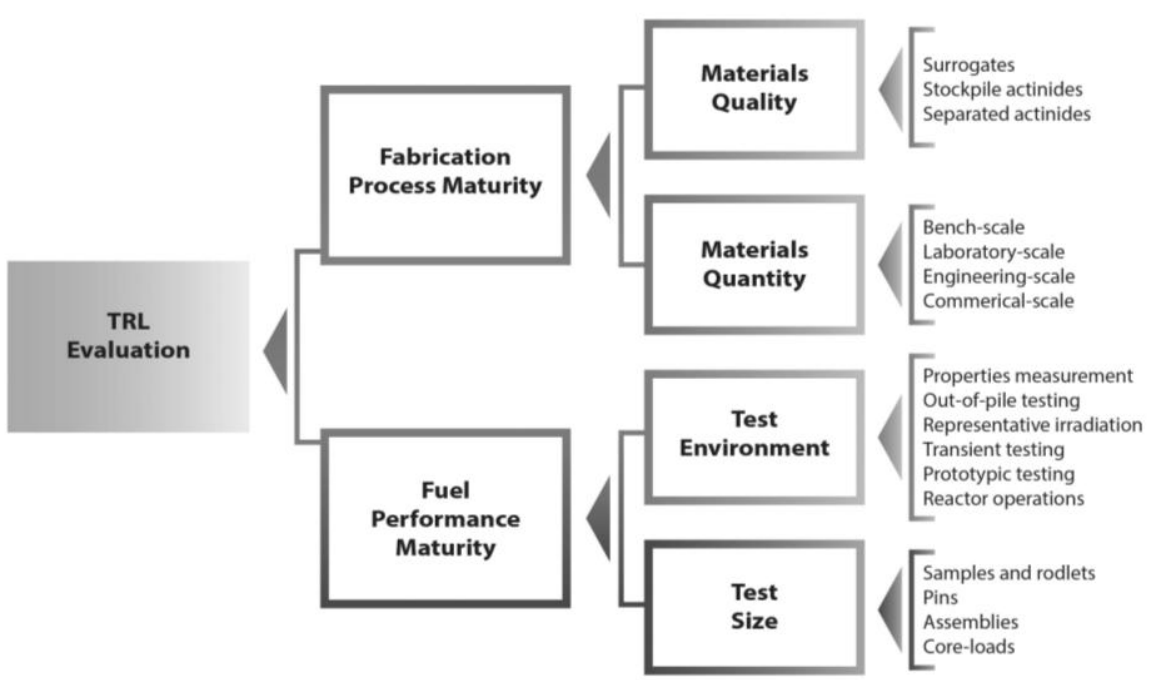

Figure 2. Summary of TRL Evaluation Elements, Attributes, and Bins.

\subsection{Fabrication Process Maturity}

To gauge the maturity of the fabrication process, there are two important attributes that must be considered:

1. Materials Used For Fabrication Process Development and Testing. This attribute is broken into three categories to gauge the TRL with respect to the materials used to fabricate the prospective fuel system.

- Surrogate Materials - These are typically nonradioactive or less-radioactive materials with properties similar to the actual fuel components. The selection of a surrogate depends on the specific phenomenon of interest and the properties that are important to predict or duplicate the phenomenon as closely as possible.

- Representative Materials from Stockpile - These are individually separated fuel component elements that must be blended together for use in fuel fabrication experiments. Quite often, the physical form of these materials is not prototypic of what would be used as final feedstock for fuel fabrication; thus, a non-prototypic conditioning step is necessary for fabrication. Also, the isotopic vectors for stockpile materials are typically different than those obtained from the final 
process when considering recycle of irradiated fuels. Those differences must be accounted for in the fabrication testing as well.

- Representative Materials from Recycling Process - Ultimately, the fabrication process must be optimized using fuel components obtained from a prototypic commercial production process or from a prototypic reprocessing/separations process, and conditioned to be used as feedstock for the fabrication of fuel.

2. Quantity of Materials Used for Fabrication Process Development and Testing. This attribute is broken into four categories to gauge the TRL. The quantity can be measured as batch size and/or throughput rate. These categories represent the development of fabrication processes beginning with research-scale efforts and progressing in scale to commercial fabrication and processing facilities.

- Bench-Scale Fabrication with gram quantities up to $100 \mathrm{~g}$ batch sizes (multiple pellets/slugs typically $1 \mathrm{~g}-1 \mathrm{~kg}$ per year).

- Laboratory-Scale Fabrication with up to $1 \mathrm{~kg}$ quantity batch sizes with an equivalent throughput rate on the order of $10 \mathrm{~kg}$ fissile/year (multiple pins/year).

- Engineering-Scale Fabrication with 1-10 kg quantity batch sizes with an equivalent throughput rate on the order of $100 \mathrm{~kg}$ fissile/year (a few assemblies/year).

- Commercial-Scale Fabrication with batch sizes that are the same order of magnitude as the engineering-scale batch sizes but at a throughput rate on the order of tons of fissile/year (a few hundred assemblies per year - core loads).

\subsection{Fuel Performance Maturity}

To gauge the maturity of fuel performance, two important attributes must be considered:

1. Test Environment to Determine Performance Parameters. This attribute is broken into six categories to assess the TRL.

- $\quad$ Fundamental Property Measurements - This category includes measurements of basic mechanical, thermal, chemical, and physical properties of samples that are fabricated through a representative process and that conform to defined specifications. If defined standard methods exist, they should be used. If standard processes do not exist, efforts to develop accepted methods should be pursued during this phase.

- Out-of-Pile Testing - This category includes experiments that while conducted without using reactor/neutron irradiations, provide insight into the behavior of fuel and cladding. Examples of such tests include diffusion-couple experiments, microstructure evolution tests, ion-beam irradiation tests, thermal segregation experiments, and oxidation and reaction kinetics.

- In-Pile Testing in Representative Spectrum - These are neutron irradiation experiments with fission where the spectrum and/or flux levels and/or thermal boundary conditions are not prototypic of the intended reactor application. Therefore, fuel design and enrichment levels may have to be adjusted to accommodate the non-prototypic nature of the irradiation environment. A good example is testing nuclear fuels using a thermal test reactor with or without partial filtering of thermal neutrons to simulate/approximate a fast neutron spectrum. Completion of the irradiation experiments implies that the associated postirradiation examination (PIE) is performed.

- Transient Testing - This category includes transient tests to mimic fuel behavior during design basis accidents and possibly beyond design basis accidents. The failure threshold determination also is covered under this category. Full-size or partial-size pins both before and after irradiation 
can be used in these tests. Irradiated pins may be those tested in representative or prototypic spectrum. Completion of the irradiation experiments implies that the associated PIE is performed.

- In-Pile Testing in Prototypic Spectrum - These irradiations are typically conducted in a reactor where flux, spectrum, and thermal effects are very similar to the actual reactor conditions for which the fuel is being licensed. Completion of the irradiation experiments implies that the associated PIE is performed.

- Reactor Operations - At this level, large quantities of fuel are used in reactor operations. PIE of selected pins may be performed to verify performance.

2. Size of Test Samples and Articles to Assess Performance Parameters. This attribute is broken into four categories to assess the TRL. In addition to size, the test geometry and cladding used in the testing campaigns are important for these categories.

- Samples \& Rodlets - This category includes; pellets, short slugs, and small quantities of materials tested in the form of individual units or small rodlets (on the order of $10 \mathrm{~cm}$ fuel height). The testing may or may not include prototypic cladding and prototypic cladding-coolant interactions. These tests are typically designed to investigate specific issues/phenomena.

- $\quad$ Pins - These tests include close to full-length pins with representative fuel heights and plenum volumes. Prototypic cladding materials are typically used in these tests.

- Assemblies - These tests contain assemblies of prototypic design. Lead fuel assemblies as well as a limited number of assemblies used for partial core conversion are included in this category. Prototypic cladding and assembly materials are used in these tests.

- Full-Cores of Assemblies - At this level, the irradiation is no longer a test program but an operations program where the statistical and long-term reliability related issues are quantified for the fuel type and design of interest.

The process of evaluating the TRL is based on categorizing each attribute. Then, given the criteria, various activities required to achieve these goals are identified as a function of the technical elements, attributes, and categories (discussed in Section 2). The resulting categorizations are shown in Figure 3 and Figure 4, for the fabrication and performance elements, respectively. The technology must be developed to the point that fabrication and performance maturity have been achieved at the appropriate scale and environment to qualify for that TRL designation.

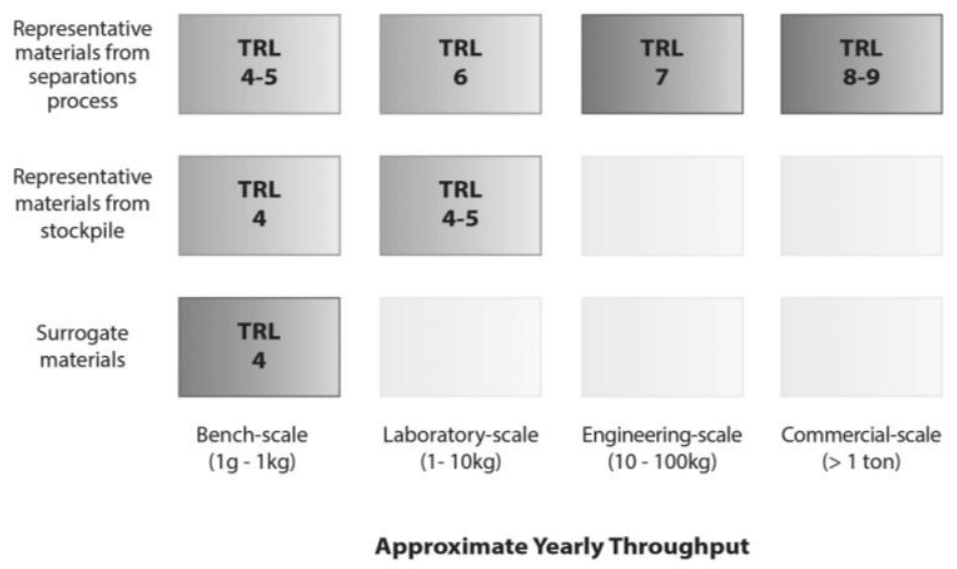

Figure 3. TRL Binning for Fabrication Process Maturity. 


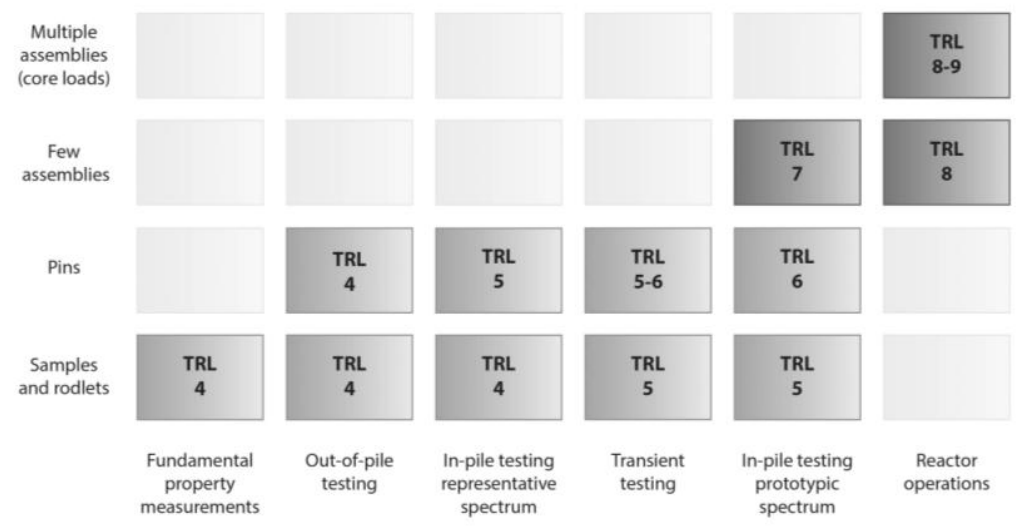

Figure 4. TRL Binning for Fuel Performance Maturity.

\subsection{Application to nuclear fuel systems}

Although a formal technology assessment should be completed, the following section provides a simple explanation of the TRL for a variety of nuclear fuel systems either in use today or currently under development as indicated in Figure 5, which provides a summary of the TRL definitions for each level and indicates a TRL ranking of various nuclear fuel systems.

\subsubsection{LWR UO $2 . \mathrm{Zr}$ fuel}

The $\mathrm{UO}_{2}$ fueled - Zirconium alloy clad fuel system used in most light water reactors (LWR) today is clearly ranked at TRL 9. The UO2-Zr fuel system is fabricated at commercial scale by a selection of commercial nuclear fuel vendors and is used in over 300 operating commercial reactors world-wide. The basis for its licensed performance envelope is available in the U.S. Nuclear Regulatory Agency (NRC) NUREG-0800 Standard Review Plan [10]. A significant body of research on the performance of the $\mathrm{UO}_{2}-\mathrm{Zr}$ fuel system can be found in the literature [11], [12].

\subsubsection{Fast reactor ( $\mathrm{U}-\mathrm{Zr}$ metal) and mixed oxide (MOX) fuels}

The sodium-cooled fast reactor (SFR) has been developed to a high technical maturity level and is in use worldwide, typically in experimental test reactors. Currently there is only one SFR, which is operated in the Russian Federation as a commercial facility (BN-600). An additional commercial-scale reactor (BN800) has begun full power operation. A variety of fuel systems have been developed for use in SFRs to various levels of maturity. Two fuel systems for SFRs that have attained a high level of maturity are the uranium-plutonium oxide (MOX) fuel system and the uranium-zirconium (U-Zr) metallic binary alloy fuel system. Both of these fuel systems have undergone similar levels of testing and development qualifying for TRL 7 to 8 . Currently, it is expected that the MOX fuel system qualifies for TRL 9 maturity level as additional commercial scale fast reactors become operational. No core load fabrication of the U-Zr binary fuel system is performed at this time but has been performed in the past in the EBR-I, Fermi, and EBR-II reactors that are now decommissioned. The historical fast reactor fuel development program fabrication, irradiation, and testing activities conducted in the United States are available in [6]. 


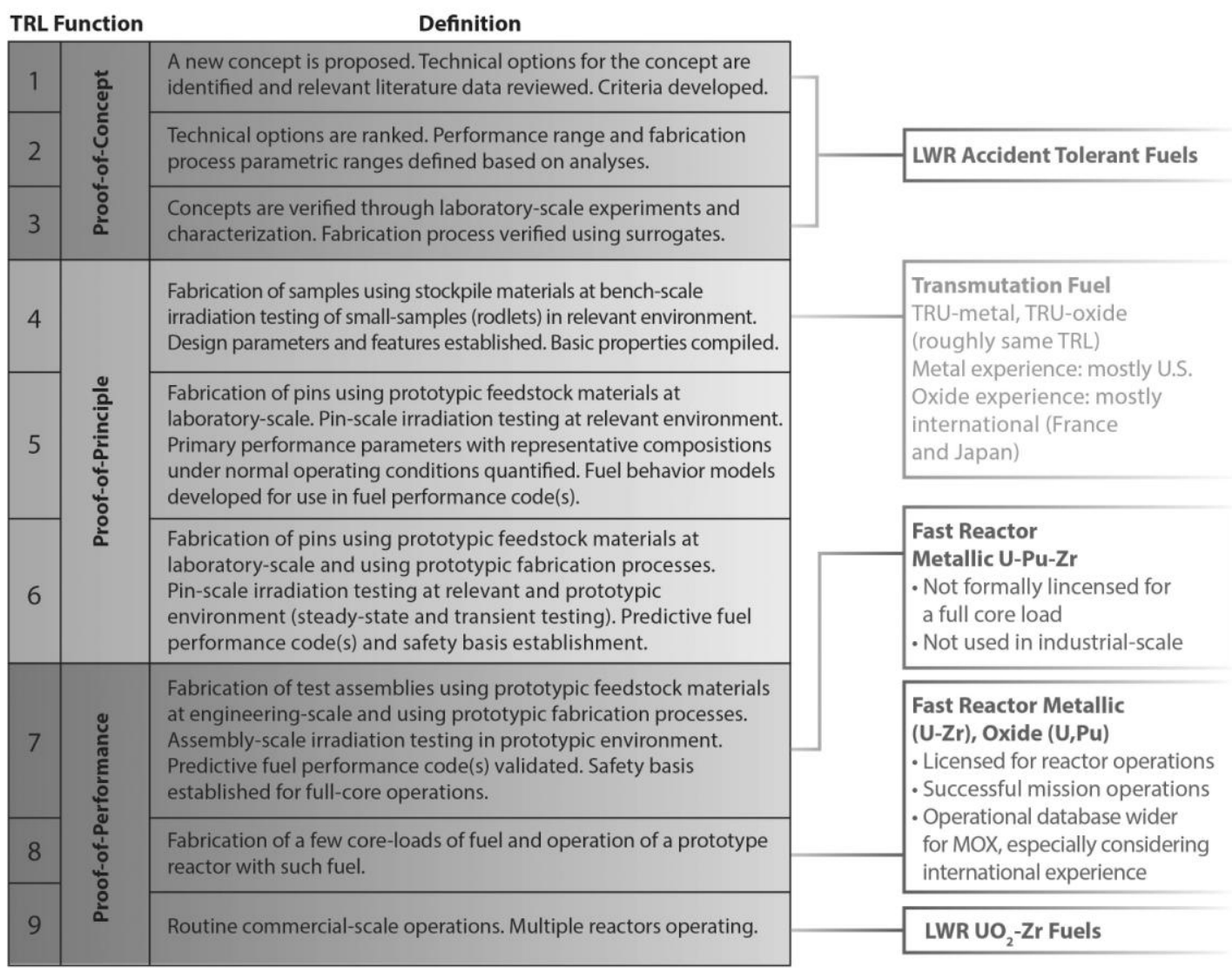

16-50176-1-RO

Figure 5. Summary of TRL Definitions for Advanced Nuclear Fuels Development.

\subsubsection{Fast reactor fuels with actinides}

Under development by a number of government and commercial industrial vendors are advanced fuels and materials for the SFR system. The performance goals for these development fuel systems vary but all either seek to achieve very high burnup operation or be utilized for management of actinides in the nuclear fuel cycle. The current status of research and development of fast reactor fuels and advanced fast reactor cladding development containing the minor actinides can be found in [13], [14], and [15].

\subsubsection{Accident tolerant fuels for LWRs}

After the events at the Fukushima-Daichii nuclear power station in Japan in March 2011, interest has increased in the development of advanced nuclear fuels and materials having enhanced performance under steady state and off-normal conditions as compared to the traditional $\mathrm{LWR} \mathrm{UO}_{2}-\mathrm{Zr}$ fuel system also referred to as "Accident Tolerant Fuels" (ATF). Multiple international institutions have engaged in the development of new fuel and material technologies for the light-water reactor system. Much of the research conducted on ATF concepts has been conducted at the bench scale and has focused primarily on out-of-pile material properties. A recent publication of U.S. Department of Energy LWR ATF research and development activities can be found in a special issue of the Journal of Nuclear Materials [16]. Research and development activities are progressing quickly in this area with bench-scale fabrication of test fuel experiments and planned irradiation in the Advanced Test Reactor (ATR) and Halden test reactors. 


\section{Summary and conclusions}

The TRL concept is used as a program management and communications tool and is not meant as an absolute quantitative measure of maturity. There is naturally a level of subjectivity in defining and in evaluating the TRLs. This article provides proposed attributes and categorization for nuclear fuel system technology readiness level definition.

It is important to recognize the difference between the TRL evaluations and technical risk. The TRL provides a measure of technology maturity compared to the end objective of large-scale deployment. A low TRL does not necessarily mean a high technical risk. Technical risk depends on many factors (e.g., the complexity of the remaining work, the availability of the needed resources, schedule constraints) and must be evaluated independently.

\section{Acknowledgments}

This manuscript has been authored by a contractor of the U.S. Government for the U.S. Department of Energy, Office of Nuclear Energy, Science, and Technology (NE), under DOE-NE Idaho Operations Office Contract DEAC0705ID14517. Accordingly, the U.S. Government retains a nonexclusive, royaltyfree license to publish or reproduce the published form of this contribution, or allow others to do so, for U.S. Government purposes.

\section{References}

[1]. NASA, 2012. Technology Readiness Levels. http://www.nasa.gov/directorates/heo/scan/engineering/technology/txt_accordion1.html (accessed 11.01.16).

[2]. Mankins, J., 1995. Technology Readiness Levels. Advanced Concepts Office, Office of Space Access and Technology. National Aeronautics and Space Administration.

[3]. DoD, 2002. Mandatory Procedures for Major Defense Acquisition Programs (MDAPS) and Major Automated Information System (MAIS) Acquisition Programs. DoD 5000.2-R, U.S. Department of Defense.

[4]. DOE, 2011. Technology Readiness Assessment Guide. DOE G 413.3-4A, U.S. Department of Energy.

[5]. Carmack, J., 2014. Technology Readiness Levels for Advanced Nuclear Fuels and Materials Development. FCRD-FUEL-2014-000577, INL/EXT-14-31243, Idaho National Laboratory.

[6]. Crawford, D., Porter, D., Hayes, S., Meyer, M., Petti, D., Pasamehmetoglu, K., 2007. An approach to fuel development and qualification. Journal of Nuclear Materials. 371, 232-242.

[7]. OECD, 2014. State -of-the-Art Report on Innovative Fuels for Advanced Nuclear Systems. Nuclear Science, NEA 6895.

[8]. Shepherd, D., 2014. TRLs for fuel and cladding. Nuclear Engineering International.

[9]. Kurata, M., 2016. Research and development methodology for practical use of accident tolerant fuel in light water reactors. Nuclear Engineering and Technology, 48(1), 26-32. 
[10]. NRC, 2007. Standard Review Plan, Rev 3. (NUREG-0800), U.S. Nuclear Regulatory Commission. Washington, D.C. March 2007.

[11]. Konings, R., 2012. Comprehensive Nuclear Materials, first ed. Elsevier Science, Amsterdam.

[12]. Hobbins, R., Petti, D., Osetek, D., Hagrman, D., 1991. Review of experimental results on light water reactor core melt progression. Nuclear Technology, 95, 287-307.

[13]. Carmack, J., Porter, D., Chang, Y., Hayes, S., Meyer, M., Burkes, D., Lee, C., Mizuno, T., Delage, F., Somers, J., 2009. Metallic fuels for advanced reactors. Journal of Nuclear Materials. Doi:10.1016/j.jnucmat.2009.03.007.

[14]. Delage, F., Carmack, J., Lee, C., Mizuno, T., Pelletier, M., Somers, J., 2013. Status of advanced fuel candidates for sodium fast reactor within the generation IV international forum. Journal of Nuclear Materials. 441 (1-3), 515-519.

[15]. Cheon, J., Lee, C., Lee, B., Raison, J., Mizuno, T., Delage, F., Carmack, J., 2009. Sodium fast reactor evaluation: Core materials. Journal of Nuclear Materials. 392 (2), 324-330.

[16]. Carmack, J., Goldner, F., 2014. Forward for special JNM issue on accident tolerant fuels for LWRs. Journal of Nuclear Materials. 448 (1-3), 373. 


\section{Appendix}

Table A.1.

TRL1 Questions for Each Critical Technology Element

\begin{tabular}{|l|l|l|}
\hline Y/N & Criteria & $\begin{array}{l}\text { Basis and Supporting } \\
\text { Documentation }\end{array}$ \\
\hline & $\begin{array}{l}\text { 1. Have the physical laws and assumptions used in new technologies } \\
\text { been defined? }\end{array}$ & \\
\hline & $\begin{array}{l}\text { 2. Have paper studies confirmed basic principles? } \\
\text { technical reports? }\end{array}$ & \\
\hline & $\begin{array}{l}\text { 4. Have the basic scientific principles forming the basis of the CTE } \\
\text { been observed and understood? }\end{array}$ & \\
\hline & $\begin{array}{l}\text { 5. Has a research hypothesis been formulated? } \\
\text { 6. Does basic characterization data exist? }\end{array}$ & \\
\hline $\begin{array}{l}\text { 7. Have the staff and facilities been identified to perform the } \\
\text { research? }\end{array}$ & \\
\hline
\end{tabular}

Table A.2.

TRL6 Questions for Each Critical Technology Element

\begin{tabular}{|c|c|c|}
\hline $\mathbf{Y} / \mathbf{N}$ & Criteria & $\begin{array}{l}\text { Basis and Supporting } \\
\text { Documentation }\end{array}$ \\
\hline & $\begin{array}{l}\text { 1. Has a Performance Baseline (including total project cost, } \\
\text { schedule, and scope) been completed? }\end{array}$ & \\
\hline & $\begin{array}{l}\text { 2. Have the operating limits been determined (from design, safety } \\
\text { and environmental compliance)? }\end{array}$ & \\
\hline & $\begin{array}{l}\text { 3. Is the operational requirements document available, including } \\
\text { implications, if any, of compliance with DOE-STD-1189-2008? }\end{array}$ & \\
\hline & $\begin{array}{l}\text { 4. Have any scaling issues that remain been identified and } \\
\text { understood, with completed supporting analysis? }\end{array}$ & \\
\hline & $\begin{array}{l}\text { 5. Has the analysis of project timing been completed to ensure the } \\
\text { technology will be available when required? }\end{array}$ & \\
\hline & 6. Have critical manufacturing processes been prototyped? & \\
\hline & 7. Is most pre-production hardware available to support fabrication? & \\
\hline & $\begin{array}{l}\text { 8. Has engineering feasibility been fully demonstrated (e.g., would it } \\
\text { work)? }\end{array}$ & \\
\hline & $\begin{array}{l}\text { 9. Have the materials, process, design, and integration methods been } \\
\text { employed (e.g., can the technology be produced)? }\end{array}$ & \\
\hline & $\begin{array}{l}\text { 10. Is the engineering-scale technology a high-fidelity functional } \\
\text { prototype of operational technology? }\end{array}$ & \\
\hline & $\begin{array}{l}\text { 11. Has a final Technical Report on the Technology been completed, } \\
\text { including implications, if any, of compliance with DOE-STD- } \\
1189-2008 \text { ? }\end{array}$ & \\
\hline & $\begin{array}{l}\text { 12. Is the process and tooling sufficiently mature to support } \\
\text { fabrication of the technology? }\end{array}$ & \\
\hline & $\begin{array}{l}\text { 13. Are engineering issues to full-scale scale-up understood and } \\
\text { resolved? }\end{array}$ & \\
\hline & $\begin{array}{l}\text { 14. Are laboratory and engineering-scale experiment results } \\
\text { consistent? }\end{array}$ & \\
\hline & $\begin{array}{l}\text { 15. Has the plan for engineering-scale testing been executed and do } \\
\text { the results validate the technology? }\end{array}$ & \\
\hline & 16. Are production demonstrations complete (at least one time)? & \\
\hline
\end{tabular}


Table A.3.

TRL9 Questions

\begin{tabular}{|l|l|l|}
\hline Y/N & Criteria & $\begin{array}{l}\text { Basis and Supporting } \\
\text { Documentation }\end{array}$ \\
\hline & $\begin{array}{l}\text { 1. Have the actual fuel and fuel assembly successfully operated in } \\
\text { the full operational environment? }\end{array}$ & \\
\hline & $\begin{array}{l}\text { 2. Is the fuel system fabricated at commercial scale and available } \\
\text { commercially? }\end{array}$ & \\
\hline
\end{tabular}

